\title{
Diagnosis and management of intestinal Behçet's disease
}

\author{
Tadakazu Hisamatsu • Makoto Naganuma • \\ Katsuyoshi Matsuoka $\cdot$ Takanori Kanai
}

Received: 30 March 2014/Accepted: 1 April 2014/Published online: 20 April 2014

(C) The Author(s) 2014. This article is published with open access at Springerlink.com

\begin{abstract}
Behçet's disease (BD) is a chronic relapsing disease with multiple organ system involvement characterized clinically by oral and genital aphthae, cutaneous lesions, and ophthalmological, neurological, and/or gastrointestinal manifestations. Little clinical evidence is available regarding the management of patients with intestinal $\mathrm{BD}$, despite recognition that the presence of intestinal lesions is a poor prognostic factor, causing perforation and massive bleeding. Many recent case reports have suggested that anti-tumor necrosis factor alpha (TNF) $\alpha$ monoclonal antibodies (mAbs) are effective in patients with intestinal BD. Adalimumab, a fully human anti-TNF $\alpha \mathrm{mAb}$, has been approved in Japan for the treatment of intestinal BD. Here, we review the pathogenesis, diagnosis and management of intestinal $\mathrm{BD}$, including evidence of the efficacy of anti-TNF $\alpha$ mAbs.
\end{abstract}

Keywords Intestinal Behçet's disease · Anti-TNF $\mathrm{mAb} \cdot$ Trisomy $8 \cdot$ Adalimumab

\author{
Abbreviations \\ ADA Adalimumab \\ BD Behçet's disease \\ CDAI Crohn's disease activity index \\ CRP C-reactive protein \\ 5-ASA 5-Aminosalicylic acid
}

T. Hisamatsu $(\bowtie) \cdot$ K. Matsuoka $\cdot$ T. Kanai

Division of Gastroenterology and Hepatology, Department of Internal Medicine, School of Medicine, Keio University,

35 Shinanomachi, Shinjuku-ku, Tokyo 160-8582, Japan

e-mail: hisamachi@a7.keio.jp

M. Naganuma

Center for Diagnostic and Therapeutic Endoscopy, School of Medicine, Keio University, Tokyo, Japan
IFX
Infliximab
$\mathrm{mAb}$
MDS
MTX
Monoclonal antibody
Myelodysplastic syndrome
Methotrexate
TNF
Tumor necrosis factor

\section{Introduction}

Behçet's disease (BD) was first defined in 1937 by Hulusi Behçet [1], a Turkish dermatologist, as a triad of recurrent aphthous stomatitis, genital aphthae and relapsing uveitis. This disease is highly prevalent along the Silk Road, including Japan, Korea, the Middle East, and the Mediterranean region.

Although intestinal lesions associated with BD may cause serious complications, such as perforation, and decreasd quality of life, the diagnosis and management of intestinal BD lesions has not been standardized. Empirical therapies have been used anecdotally to treat intestinal BD. In Japan, adalimumab (ADA), an anti-tumor necrosis factor alpha (TNF $\alpha$ ) monoclonal antibody (mAb), was approved for the treatment of intestinal BD in 2013. The introduction of anti-TNF $\alpha$ mAbs has altered treatment strategies and may improve the long-term prognosis of patients with intestinal BD. Here, we review current topics in intestinal $\mathrm{BD}$, including its clinical characteristics, diagnosis, and management.

\section{Diagnosis of intestinal Behçet's disease}

$\mathrm{BD}$ is regarded as a chronic relapsing disease with multiple organ system involvement characterized clinically by oral 

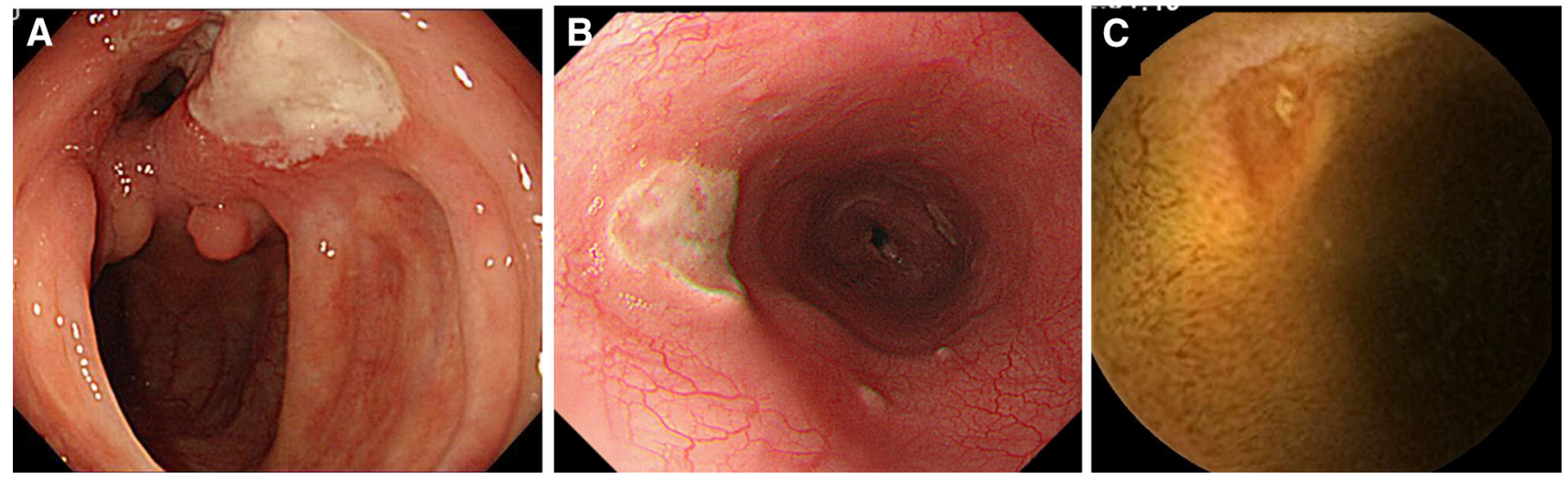

Fig. 1 Gastrointestinal lesions in BD. a A typical giant oval-shaped deep punched-out ulcer in the ileocecal area. b An atypical ovalshaped ulcer in the middle part of the esophagus in a patient with

and genital aphthae, cutaneous lesions, and ophthalmological, neurological, and/or gastrointestinal manifestations $[2,3]$. Several diagnostic criteria for BD have been proposed. The widely used International Study Group (ISG) for Behçet's disease criteria include recurrent oral ulcer, plus at least two of the following four factors-recurrent genital ulcers, eye lesions, skin lesions, and positive pathergy test [4]. The Japanese criteria proposed in 2004 are also widely used [5].

Approximately 3-16\% of patients with BD have gastrointestinal tract involvement [6]. A retrospective analysis of 2,313 patients with BD found that the male/female patient ratio was 1.03 , with gastrointestinal involvement present in $1.4 \%$ of both males and females [7]. A typical gastrointestinal lesion consists of a giant oval-shaped deep punched-out ulcer in the ileocecal area (Fig. 1a); however, involvement of the esophagus and small intestine has also been reported. The most common gastrointestinal symptoms are abdominal pain, diarrhea, and bleeding. Deep ulcers are responsible for the most common intestinal complications, such as severe bleeding and perforation. Therefore, intestinal lesions have been considered a factor associated with poor prognosis in BD patients, resulting in emergency abdominal surgery and bowel resection [8].

Confusion has arisen regarding the terminology used to describe this condition. Among the terms used are 'intestinal BD', 'entero-BD', and 'intestinal lesions associated with BD', with the various terms possibly due to a lack of standardized diagnostic criteria. In this review, we use the term 'intestinal BD' according to the diagnostic criteria reported by Kobayashi et al. [9]. Briefly, intestinal BD is diagnosed in patients meeting the Japanese diagnostic criteria of BD [5], by the presence of a typical oval-shaped large ulcer in the ileocecum. However, we have often encountered patients with these ulcers in the ileocecum who do not have typical BD manifestations. These patients, who intestinal BD. c A discrete ulcer in the small intestine detected by capsule endoscopy in a MDS patient associated with trisomy 8

cannot be diagnosed with intestinal BD by Japanese criteria, have been described as having 'simple ulcer syndrome' [10]. To date, similarities and differences in the pathogenesis, histopathology, and prognosis of Japanese patients with intestinal BD and simple ulcer syndrome have not been identified, although neutrophilic phlebitis may be involved in the pathogenesis of both [11]. The clinical manifestations of BD often show spatial and temporal diversity, making it difficult to differentiate between intestinal BD and simple ulcer syndrome in some patients. In addition, we often encounter patients with $\mathrm{BD}$ and atypical gastrointestinal lesions. Again, similarities and differences in the pathogenesis of these atypical lesions and typical oval-shaped ulcers have not been identified. A Korean group proposed novel diagnostic criteria for intestinal BD in Korean patients with ileocolonic ulcers [12]. They suggested that systemic BD patients with typical ileocecal ulcers should be diagnosed as having 'definite intestinal BD', patients with typical ileocecal ulcer and oral ulcers and patients with systemic BD and atypical ulcers should be diagnosed as having 'probable intestinal BD', and patients with typical ileocecal ulcers without any BD symptoms should be diagnosed with 'suspected intestinal BD'.

Although an oval-shaped ulcer at the ileocecum is considered typical of intestinal $\mathrm{BD}$, esophageal lesions have also been reportedly associated with BD [13-17] (Fig. 1b). For example, one study reported that the incidence of esophageal involvement was relatively low (11\%) [18], and a retrospective analysis of 842 Korean patients diagnosed with BD found that 129 (15.3\%) experienced upper gastrointestinal symptoms, but esophageal involvement was found in only six $(4.7 \%)$ of these 129 patients [19]. Esophageal lesions may be helpful in the diagnosis of intestinal $\mathrm{BD}$, but the necessity of upper gastrointestinal examination in asymptomatic BD patients has not been determined. 
Fig. 2 Differential diagnosis of intestinal BD. a Annular ulcers in patients with active TB. b Longitudinal ulcers and a cobblestone appearance in a patient with $\mathrm{CD}$
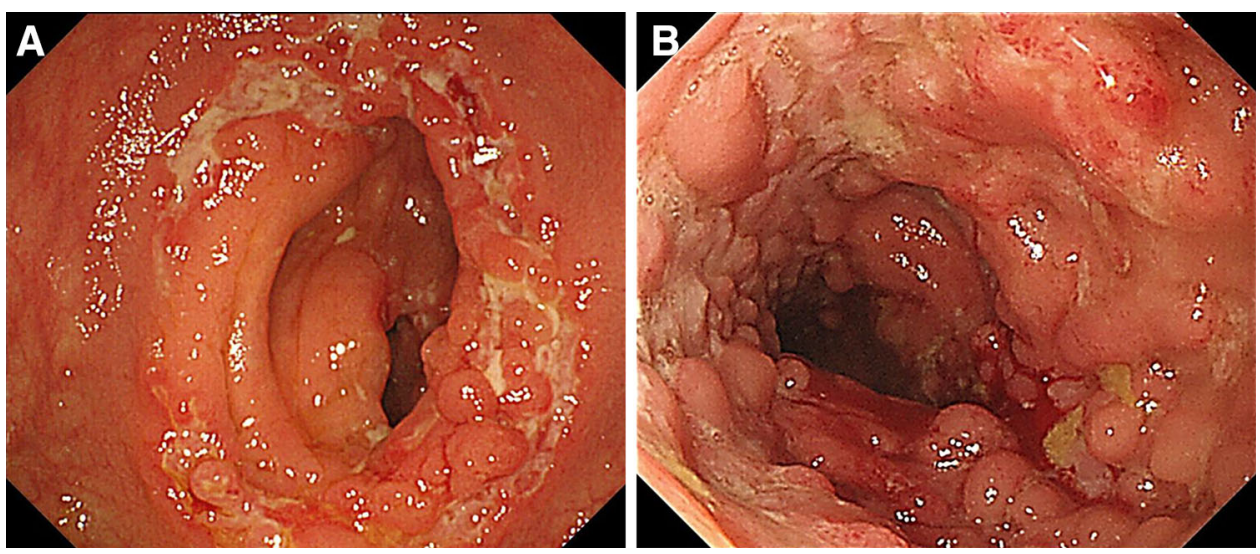

\section{Differential diagnosis of intestinal BD}

Intestinal tuberculosis (TB), Crohn's disease (CD), and other diseases with intestinal ulceration should be excluded. Ruling out intestinal $\mathrm{TB}$ is especially important, because the immunosuppressive therapy used to treat $\mathrm{BD}$, including corticosteroids and anti-TNF $\alpha$ mAbs, can exacerbate intestinal TB. Methods of diagnosing intestinal TB include tissue culture, tissue PCR and interferon-gamma release assays (IGRA), in addition to general examinations such as chest X-ray and tuberculin test. Endoscopic findings of intestinal TB often include annular ulcer and scarred areas with discoloration (Fig. 2a).

The differential diagnosis between intestinal $\mathrm{BD}$ and $\mathrm{CD}$ is often difficult, since several extraintestinal manifestations, such as oral ulcers and arthralgia, are seen in both diseases. Typical endoscopic and radiological findings in patients with CD include longitudinal ulcers and a cobblestone appearance (Fig. 2b). Anal lesions are more common in $\mathrm{CD}$ than in intestinal BD. Balloon small intestinal endoscopy and capsule endoscopy have recently been reported to be useful for the diagnosis and monitoring of patients with intestinal BD [20-23] (Fig. 1c).

\section{Pathogenesis of intestinal BD}

\section{Genetic factors}

Few cases of familial intestinal BD have been reported to date, suggesting the contribution of genetic factors in its pathogenesis [24, 25]. Recently, genome-wide association studies (GWAS) have identified several genes associated with susceptibility to BD including the interleukin (IL)23R, IL-10, STAT, and HLA-B51 genes [26-29]. However, few genetic factors associated with the phenotype of intestinal $\mathrm{BD}$ have been identified. The positive ratio of HLA-B51 has been reported to be lower in patients with intestinal BD associated with myelodysplastic syndrome (MDS) than in BD patients without intestinal involvement [18]. The number of copies of the DEFAl gene, which encodes $\alpha$-defensin-1, has been reported to correlate with intestinal involvement in BD [30], and familial cases of BD with intestinal lesions have been reported to be associated with NEMO mutations [31].

Immunological abnormalities

Susceptible genes identified by GWAS strongly suggest that abnormal immunological responses may play a role in the pathogenesis of $\mathrm{BD}$. However, the precise mechanisms underlying the pathogenesis of intestinal BD have not yet been identified. Abnormal innate immune responses have been reported to be associated with intestinal $\operatorname{BD}[30,32]$. Moreover, tissue samples taken from intestinal lesions of $\mathrm{BD}$ have been found to express interferon gamma (IFN $\gamma$ ), TNF $\alpha$ and IL-12 mRNAs, indicating skewed Th1 responses [33]. Similarly, an investigation of cytokine expression in ileal biopsy specimens from patients with intestinal BD reported Th1 skewing [34]. Recent reports showing the efficacy of anti-TNF $\alpha \mathrm{mAb}$ suggest the importance of $\mathrm{TNF} \alpha$ in the pathogenesis of intestinal BD.

Trisomy 8 and intestinal ulcers

Although BD and MDS are two different disease entities, some BD patients have bone marrow disorders such as MDS and aplastic anemia. MDS is a clonal hematologic disease with cytogenetic abnormalities. The most common chromosomal abnormality in BD patients with MDS is trisomy 8. A review of 62 Japanese patients with BD-associated MDS found that, among the 45 patients with abnormal karyotypes, 39 (86.7\%) had trisomy 8 [35]. Similarly, an analysis of the clinical features of 13 patients with $\mathrm{BD}$ and bone marrow disorders found that seven (54\%) had trisomy 8 [36]. Trisomy 8 may also be 
associated with the development of intestinal ulcers in patients with MDS [37]. The mechanisms by which trisomy 8 is associated with intestinal ulcers has not been determined, although autoimmune mechanisms play a role in the development of hematopoietic disorders such as MDS and aplastic anemia [38, 39]. Gene expression analysis of $\mathrm{CD}_{3}{ }^{+}$hematopoietic cells in patients with trisomy 8 showed over-expression of proinflammatory cytokines [40]. In addition, trisomy 8 was associated with low copy numbers of the human beta-defensin 2 gene, which plays a role in human innate immunity [41]. Interestingly, a case report showed atypical endoscopic findings of intestinal ulcers in patients with BD and trisomy 8 [42], differing from the typical endoscopic findings of a giant oval punched-out ulcer at the ileocecum. Further investigations are needed to assess the similarities and differences between intestinal BD and intestinal ulcers in BD patients with trisomy 8 .

\section{Management and therapy}

Conventional treatments and disease prognosis

Clinical evidence regarding the management of patients with intestinal BD is limited. Among the agents used empirically, 5-aminosalicylic acid (5-ASA), systemic corticosteroids, thalidomide, colchicine and immunosuppressive agents have been used. A study in Korea showed that 5-ASA/sulfasalazine therapy could maintain remission in patients with intestinal $\mathrm{BD}$, although younger age ( $<35$ years), higher C-reactive protein (CRP) level, and higher disease activity were associated with a poor response to 5-ASA/sulfasalazine [43]. Mesalazine was shown to have benefits in the treatment of esophageal ulcers in a patient with intestinal BD [44]. Corticosteroids are generally used to induce clinical remission in intestinal BD patients with moderate to severe activity [15, 45-47]. Immunosuppressants have also been used successfully. For example, a retrospective analysis of 272 patients with intestinal BD in a single center described the efficacy of thiopurine maintenance therapy. Of these 272 patients, 67 (24.6\%) received their first course of thiopurine therapy in the center, with $39(58.2 \%)$ of these 67 patients maintained on thiopurines. The cumulative 1-, 2-, 3- and 5-year relapse rates after remission were 5.8, 28.7, 43.7, and $51.7 \%$, respectively [48]. Methotrexate (MTX) has also been used to treat refractory intestinal BD [49]. Oral tacrolimus was effective in a patient with intestinal BD [50], and thalidomide, an agent with anti-inflammatory and immunomodulatory properties, has also been found to be effective [51-53].

In response to a request to standardize treatment of intestinal BD, the Japanese Inflammatory Bowel Disease
Research Group, supported by the Japanese Ministry of Health, Labour and Welfare, proposed the first set of consensus statements in 2007 for the management of intestinal BD [9]. This consensus recommended systemic corticosteroids for induction therapy and thiopurines for refractory intestinal BD as standard therapies, with anti$\mathrm{TNF} \alpha \mathrm{mAb}$ described as optional.

Despite reports showing the beneficial effect of medical therapies, patients with intestinal $\mathrm{BD}$ often require surgical treatment and may develop post-operative recurrence. Thus, intestinal BD, in at least a subpopulation of patients, should be considered a progressive disorder that causes disability, similar to CD. Since it is difficult to predict which patients will experience complicated disease courses, therapy should be individualized and depend on monitoring of individual patients. In our retrospective analysis of 20 patients, ocular and ileal lesions were risks for surgery [54]. Postoperative recurrence of intestinal ulcers was observed in seven of nine patients with intestinal BD who had undergone a total of 15 operations [55]. A retrospective analysis of 72 Korean patients with intestinal BD who underwent surgery showed that $42(58.3 \%)$ experienced recurrence after surgery, with 22 (30.6\%) requiring re-operations. The cumulative 2- and 5-year recurrence rates after surgery were 29.2 and $47.2 \%$, respectively [56]. A retrospective evaluation of 130 patients with intestinal BD during the first 5 years after diagnosis revealed five different clinical courses, with the most frequent being persistent remission or mild clinical activity $(56.2 \%)$ and only $16.2 \%$ having a severe clinical course. Younger age, higher erythrocyte sedimentation rate (ESR), CRP concentration, and disease activity index, and lower albumin concentration at diagnosis were factors associated with poor patient prognosis [57].

\section{Anti-TNF $\alpha$ monoclonal antibodies}

The efficacy of anti-TNF $\alpha$ mAbs in intestinal BD was first reported in 2001. Treatment with infliximab (IFX) of two patients with intestinal BD resistant to conventional therapy, including prednisolone, one with $3 \mathrm{mg} / \mathrm{kg}$ and the other with $5 \mathrm{mg} / \mathrm{kg}$ IFX, resulted in the rapid (within 10 days) reduction of intestinal lesions and extraintestinal manifestations [53]. Remission in both patients was maintained with thalidomide, not IFX. In addition, a patient with chronically active, steroid-dependent BD involving the gastrointestinal tract who was treated with four doses of IFX over a period of 6 months showed a reduction in $\mathrm{CD}$ activity index (CDAI) from 270 points before infusion to 13 points by week 2 , with remission sustained despite the complete withdrawal of steroids [58]. Colonoscopy 10 weeks after the first infusion showed marked endoscopic and histological improvement. After 
these reports suggesting the rapid efficacy of IFX, several groups have assessed the efficacy of anti-TNF $\alpha$ in intestinal BD [59, 60]. For example, six Japanese patients with intestinal $\mathrm{BD}$, all of whom were steroid dependent and refractory to other treatments, received IFX induction therapy $(5 \mathrm{mg} / \mathrm{kg}$ at 0,2 , and 6 weeks), followed by maintenance therapy every 8 weeks [61]. Four of these six patients achieved and maintained remission with IFX. The other two patients, both of whom had ileal ulceration, required surgery, but one has maintained remission by IFX after surgery. A retrospective analysis of 28 patients with intestinal BD who received at least 1 dose of IFX and were followed-up for a median 29.5 months, resulted in response rates to IFX at 2, 4, 30, and 54 weeks of 75, 64.3, 50, and $39.1 \%$, respectively, and clinical remission rates of 32.1, 28.6, 46.2, and 39.1\%, respectively [62]. Multivariate analysis indicated that older age at diagnosis ( $\geq 40$ years), female sex, longer disease duration ( $\geq 5$ years), concomitant immunomodulator use, and achievement of remission at week 4 were predictive of sustained response. BD patients with intestinal lesions have a risk of multiple operations, but postoperative use of anti-TNF $\alpha$ has not been shown to reduce postoperative relapse rates and risk of multiple operations. IFX was used as rescue therapy for a patient with an unhealed anastomosis site and early recurrent ulcers after bowel resection [63]. IFX has also been reported effective in treating pediatric patients with intestinal $\mathrm{BD}$, including a 15 -year-old girl with refractory intestinal BD who responded rapidly to IFX [64] and a pediatric patient with progressive, refractory pediatric $\mathrm{BD}$ with intestinal lesions who responded to IFX [65].

Fewer reports have described the clinical efficacy of ADA. One patient with intestinal BD was treated with ADA monotherapy [66], whereas another was diagnosed with intestinal $\mathrm{BD}$ despite $\mathrm{ADA}$ treatment for underlying ankylosing spondylitis [67]. In Japan, a phase 3, nonrandomized, non-controlled, one-arm, clinical trial tested ADA for intestinal BD [68]. Patients were given $160 \mathrm{mg}$ $\mathrm{ADA}$ at week $0,80 \mathrm{mg}$ at week 2 , and $40 \mathrm{mg}$ every other week, beginning at week 4 . The primary endpoint was 'marked improvement' rate at week 24, with 'marked improvement' defined according to the physicians' global assessment of gastrointestinal symptoms and endoscopic improvement. The 'marked improvement' and complete remission rates at week 24 were 45 and $20 \%$, respectively. Based on the results of this clinical trial, ADA was approved in Japan to treat intestinal BD in May 2013. A clinical trial has also tested IFX for intestinal BD in Japan, and the second edition of consensus statements for the diagnosis and management of intestinal $\mathrm{BD}$ has proposed anti-TNF $\alpha \mathrm{mAb}$ as a standard therapy for patients with moderate to severe intestinal BD [68].
Can anti-TNF $\alpha$ mAb change therapeutic strategy of intestinal BD?

$\mathrm{CD}$ is regarded as a progressive disability of the digestive tract. Early intervention with anti-TNF $\alpha$ mAbs may alter the natural history of $\mathrm{CD}$ and improve the long-term prognosis of patients with this disorder [69]. Sub-types of $\mathrm{BD}$ are also progressive diseases, with BD uveitis causing loss of vision and intestinal BD requiring bowel resection. Thus, it is important to determine if anti-TNF $\alpha \mathrm{mAb}$ treatment can improve the long-term prognosis of these patients. Although anti-TNF $\alpha \mathrm{mAb}$ has been reported to reduce the risk of visual loss in patients with $\mathrm{BD}$ uveitis [70], its ability to reduce the risk of surgery in patients with intestinal BD has not been fully investigated. Since clinical symptoms and clinical activity index are often subjective in inflammatory bowel disease (IBD), discrepancies between clinical symptoms and endoscopic findings have been observed in IBD patients. Therefore, endoscopic findings are regarded as more important in evaluating the management of IBD patients. Mucosal healing, defined as endoscopic remission, has become the goal of IBD treatment to improve the long-term prognosis [71]. In contrast, there is no evidence indicating that mucosal healing should be a treatment target for improving the long-term prognosis of patients with intestinal $\mathrm{BD}$, although the concept of 'mucosal healing' may be applicable in the management of these patients (Fig. 3a, b). For example, an analysis of 10 patients with intestinal BD who were treated with IFX and MTX reported that ileocecal ulcerations disappeared in nine of these patients $(90 \%) 12$ months after initiation of IFX [49]. A patient with intestinal BD who was treated with IFX monotherapy successfully maintained clinical remission and complete mucosal healing for 6 years [72]. A retrospective analysis of the correlation between endoscopic parameters and clinical activity index in 167 patients with intestinal BD found that, although the number of intestinal ulcers and volcano-shaped ulcers were predictive of severe clinical index score, the correlation between endoscopic severity and clinical activity index was weak [73].

Thus, as in IBD, anti-TNF $\alpha$ mAb treatment may achieve mucosal healing and improve the long-term prognosis in patients with intestinal $\mathrm{BD}$. To ensure the maximal efficacy of anti-TNF $\alpha$ mAb therapy, the concept of 'early CD' has been proposed. Subgroup analysis of the CHARM trial showed that ADA was superior to placebo in maintaining clinical remission in patients with moderately to severely active CD after 1 year of treatment, regardless of disease duration [74]. Clinical remission rates through 3 years of treatment were highest in the group with the shortest disease duration. However, the optimal timing of anti-TNF $\alpha$ $\mathrm{mAb}$ treatment in intestinal BD has not been determined. 
Fig. 3 IFX treatment can induce 'mucosal healing' of intestinal BD lesions. a A typical giant oval-shaped ulcer observed before initiation of IFX. b Dramatic improvement of ileocecal lesions after treatment with IFX (the patient was reported by Maruyama et al. [72])
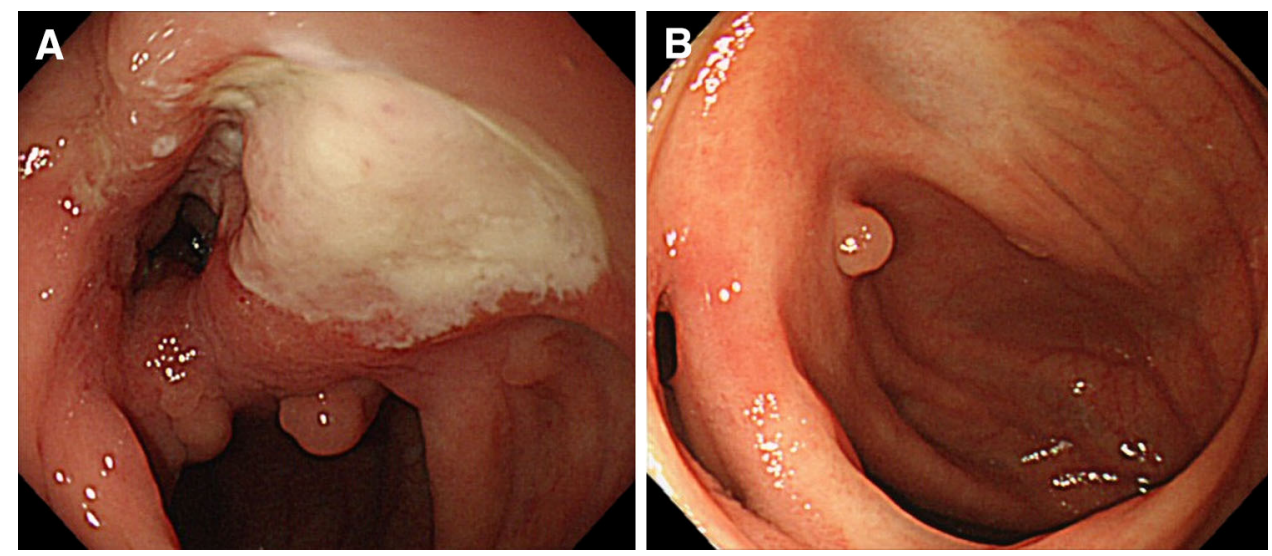

Despite anecdotal evidence showing the efficacy of combinations of immunomodulators with anti-TNF $\alpha$ mAbs as induction and maintenance treatment in intestinal $\mathrm{BD}$, there is no consensus regarding their use. Even in $\mathrm{CD}$, it remains unresolved whether anti-TNF $\alpha$ mAbs should be used in combination with immunomodulators [75-78]. Although one study reported the effectiveness of MTX plus IFX [49], another described a patient successfully maintained with IFX monotherapy [72].

\section{Conclusion}

In reviewing the latest reports on the diagnosis and management of intestinal BD, we found that anti-TNF $\alpha \mathrm{mAb}$ is a promising treatment for patients with this disorder. However, several issues remain to be resolved. Genomic analysis of patients with intestinal $\mathrm{BD}$, as well as determining the mechanism of action of anti-TNF $\alpha$ mAbs, may provide insight into the pathogenesis of this disorder. Clinically, it is necessary to formulate global diagnostic criteria and an objective disease activity index. Treatment with anti-TNF $\alpha$ mAbs will likely alter disease prognosis, although these agents are not necessary in all patients with intestinal BD. Most importantly, it is necessary to identify high-risk patients and to monitor their disease activity.

Acknowledgments This study was supported by Grants-in-Aid from the Japanese Ministry of Education, Culture, Sports, Science and Technology; the Japanese Ministry of Health, Labour and Welfare; and Keio University Medical Fund.

\section{Disclosures}

Conflict of Interest: Tadakazu Hisamatsu received a research grant from Ajinomoto Pharmaceuticals Co., LTD and Eisai Co., LTD, and honoraria from Abbvie. Makoto Naganuma declare that he has no conflict interest. Katsuyoshi Matsuoka received a research grant from Mitsubishi Tanabe Pharma Corporation. Takanori Kanai received a research grant from Mitsubishi Tanabe Pharma Corporation, Eisai Co., LTD, Abbvie, JIMRO Co., LTD, Takeda Pharmaceutical Co., LTD, and ZERIA Co., LTD.
Human/Animal Rights: All procedures followed were in accordance with the ethical standards of the responsible committee on human experimentation (institutional and national) and with the Helsinki Declaration of 1975, as revised in 2008(5).

Informed Consent: This review article does not have relevant issues of informed consent disclosure to be reported.

Open Access This article is distributed under the terms of the Creative Commons Attribution License which permits any use, distribution, and reproduction in any medium, provided the original author(s) and the source are credited.

\section{References}

1. Behçet H. Uber rezidivierende, aphthose, durch ein Virus verursachte Geschwire am Mund, am Auge und an den Genitalen. Dermatol Wochenschr. 1937;105:1152-7.

2. Garton RA, Ghate JV, Jorizzo JL. Behçet's disease. In: Harris Jr ED, Budd RC, Genovese MC, Firestein GS, Sargent JS, Sledge $\mathrm{CB}$, editors. Textbook of rheumatology. 7th ed. Philadelphia: Saunders; 2005.

3. Krause I, Weinberger A. Behçet's disease. Curr Opin Rheumatol. 2008;20:82-7.

4. Criteria for diagnosis of Behçet's disease. International study group for Behçet's disease. Lancet. 1990;335:1078-80.

5. Suzuki Kurokawa M, Suzuki N. Behcet's disease. Clin Exp Med. 2004:4:10-20.

6. Sakane T, Takeno M, Suzuki N, Inaba G. Behçet's disease. N Engl J Med. 1999;341:1284-91.

7. Tursen U, Gurler A, Boyvat A. Evaluation of clinical findings according to sex in 2313 Turkish patients with Behçet's disease. Int J Dermatol. 2003;42:346-51.

8. Brandt LJ, Boley SJ. Intestinal ischemia. In: Feldman M, Friedman LS, Sleisenger MH, editors. Gastrointestinal and liver disease. 7th ed. Philadelphia: Saunders; 2002.

9. Kobayashi K, Ueno F, Bito S, Iwao Y, Fukushima T, Hiwatashi $\mathrm{N}$, et al. Development of consensus statements for the diagnosis and management of intestinal Behçet's disease using a modified Delphi approach. J Gastroenterol. 2007;42:737-45.

10. Muto T. Iwayuru "simple ulcer" towa. (Historical review of so called "simple ulcer" of the intestine.) I to Chou. (Stomach Intestine.) 1979;14:739-48. (in Japanese).

11. Hayasaki N, Ito M, Suzuki T, Ina K, Ando T, Kusugami K, et al. Neutrophilic phlebitis is characteristic of intestinal Behçet's disease and simple ulcer syndrome. Histopathology. 2004;45:377-83. 
12. Cheon JH, Kim ES, Shin SJ, Kim TI, Lee KM, Kim SW, et al. Development and validation of novel diagnostic criteria for intestinal Behçet's disease in Korean patients with ileocolonic ulcers. Am J Gastroenterol. 2009; 104:2492-9.

13. Lorenzetti ME, Forbes IJ, Roberts-Thomson IC. Oesophageal and ileal ulceration in Behçet's disease. J Gastroenterol Hepatol. 1990;5:714-7.

14. Ikezawa K, Kashimura H, Hassan M, Nakahara A, Yanaka A, Matsuzaki Y, et al. A case of Behçet's syndrome with esophageal involvement treated with salicylazosulfapyridine and prednisolone. Endoscopy. 1998;30:S52-3.

15. Yasuo M, Miyabayashi H, Okano T, Aoki H, Ichikawa K, Hirose Y. Successful treatment with corticosteroid in a case of Behçet's syndrome with multiple esophageal ulcerations. Intern Med. 2003;42:696-9.

16. Yokota K, Hirano M, Akiba H, Adachi D, Takeishi M, Akiyama $\mathrm{Y}$, et al. A case of Behçet's disease with esophageal ulcers complicated with systemic sclerosis, chronic hepatitis $\mathrm{C}$, and pancytopenia. Nihon Rinsho Meneki Gakkai Kaishi. 2004;27:164-70.

17. Fujiwara S, Shimizu I, Ishikawa M, Uehara K, Yamamoto $H$, Okazaki M, et al. Intestinal Behcet's disease with esophageal ulcers and colonic longitudinal ulcers. World J Gastroenterol. 2006;12:2622-4.

18. Bottomley WW, Dakkak M, Walton S, Bennett JR. Esophageal involvement in Behçet's disease. Is endoscopy necessary? Dig Dis Sci. 1992;37:594-7.

19. Yi SW, Cheon JH, Kim JH, Lee SK, Kim TI, Lee YC, et al. The prevalence and clinical characteristics of esophageal involvement in patients with Behçet's disease: a single center experience in Korea. J Korean Med Sci. 2009;24:52-6.

20. Chang DK, Kim JJ, Choi H, Eun CS, Han DS, Byeon JS, et al. Double balloon endoscopy in small intestinal Crohn's disease and other inflammatory diseases such as cryptogenic multifocal ulcerous stenosing enteritis (CMUSE). Gastrointest Endosc. 2007;66:S96-8.

21. Gubler C, Bauerfeind P. Intestinal Behçet's disease diagnosed by capsule endoscopy. Endoscopy. 2005;37:689.

22. Hamdulay SS, Cheent K, Ghosh C, Stocks J, Ghosh S, Haskard DO. Wireless capsule endoscopy in the investigation of intestinal Behçet's syndrome. Rheumatology (Oxford). 2008;47:1231-4.

23. Neves FS, Fylyk SN, Lage LV, Ishioka S, Goldenstein-Schainberg C, Sakai P, et al. Behçet's disease: clinical value of the video capsule endoscopy for small intestine examination. Rheumatol Int. 2009;29:601-3.

24. Chong VF, Pathmanathan R. Familial Behçet's syndrome with intestinal involvement-case reports and a review of the literature. Ann Acad Med Singapore. 1993;22:807-10.

25. Kobayashi T, Sudo Y, Okamura S, Ohashi S, Urano F, Hosoi T, et al. Monozygotic twins concordant for intestinal Behçet's disease. J Gastroenterol. 2005;40:421-5.

26. Mizuki N, Meguro A, Ota M, Ohno S, Shiota T, Kawagoe T, et al. Genome-wide association studies identify IL23R-IL12RB2 and IL10 as Behçet's disease susceptibility loci. Nat Genet. 2010;42:703-6.

27. Remmers EF, Cosan F, Kirino Y, Ombrello MJ, Abaci N, Satorius $\mathrm{C}$, et al. Genome-wide association study identifies variants in the MHC class I, IL10, and IL23R-IL12RB2 regions associated with Behçet's disease. Nat Genet. 2010;42:698-702.

28. Lee YJ, Horie Y, Wallace GR, Choi YS, Park JA, Choi JY, et al. Genome-wide association study identifies GIMAP as a novel susceptibility locus for Behcet's disease. Ann Rheum Dis. 2013;72:1510-6.

29. Hou S, Yang Z, Du L, Jiang Z, Shu Q, Chen Y, et al. Identification of a susceptibility locus in STAT4 for Behçet's disease in
Han Chinese in a genome-wide association study. Arthr Rheum. 2012;64:4104-13.

30. Ahn JK, Cha HS, Lee J, Jeon $\mathrm{CH}$, Koh EM. Correlation of DEFA1 gene copy number variation with intestinal involvement in Behcet's disease. J Korean Med Sci. 2012;27:107-9.

31. Takada H, Nomura A, Ishimura M, Ichiyama M, Ohga S, Hara T. NEMO mutation as a cause of familial occurrence of Behçet's disease in female patients. Clin Genet. 2010;78:575-9.

32. Nara K, Kurokawa MS, Chiba S, Yoshikawa H, Tsukikawa S, Matsuda T, et al. Involvement of innate immunity in the pathogenesis of intestinal Behçet's disease. Clin Exp Immunol. 2008;152:245-51.

33. Imamura Y, Kurokawa MS, Yoshikawa H, Nara K, Takada E, Masuda C, et al. Involvement of Th1 cells and heat shock protein 60 in the pathogenesis of intestinal Behcet's disease. Clin Exp Immunol. 2005;139:371-8.

34. Ferrante A, Ciccia F, Principato A, Giardina AR, Impastato R, Peralta $\mathrm{S}$, et al. A Th1 but not a Th17 response is present in the gastrointestinal involvement of Behçet's disease. Clin Exp Rheumatol. 2010;28:S27-30.

35. Tada Y, Koarada S, Haruta Y, Mitamura M, Ohta A, Nagasawa $\mathrm{K}$. The association of Behçet's disease with myelodysplastic syndrome in Japan: a review of the literature. Clin Exp Rheumatol. 2006;24:S115-9.

36. Ahn JK, Cha HS, Koh EM, Kim SH, Kim YG, Lee CK, et al. Behcet's disease associated with bone marrow failure in Korean patients: clinical characteristics and the association of intestinal ulceration and trisomy 8. Rheumatology (Oxford). 2008;47:1228-30.

37. Kimura S, Kuroda J, Akaogi T, Hayashi H, Kobayashi Y, Kondo M. Trisomy 8 involved in myelodysplastic syndromes as a risk factor for intestinal ulcers and thrombosis-Behçet's syndrome. Leuk Lymphoma. 2001;42:115-21.

38. Voulgarelis M, Giannouli S, Ritis K, Tzioufas AG. Myelodysplasia-associated autoimmunity: clinical and pathophysiologic concepts. Eur J Clin Invest. 2004;34:690-700.

39. Hsu HC, Lee YM, Tsai WH, Jiang ML, Ho CH, Ho CK, et al. Circulating levels of thrombopoietic and inflammatory cytokines in patients with acute myeloblastic leukemia and myelodysplastic syndrome. Oncology. 2002;63:64-9.

40. Zeng W, Chen G, Kajigaya S, Nunez O, Charrow A, Billings EM, et al. Gene expression profiling in CD34 cells to identify differences between aplastic anemia patients and healthy volunteers. Blood. 2004;103:325-32.

41. Fellermann K, Stange DE, Schaeffeler E, Schmalzl H, Wehkamp $\mathrm{J}$, Bevins CL, et al. A chromosome 8 gene-cluster polymorphism with low human beta-defensin 2 gene copy number predisposes to Crohn disease of the colon. Am J Hum Genet. 2006;79:439-48.

42. Tanaka H, Shimizu N, Tougasaki E, Kawajiri C, Hashimoto S, Takeda Y, et al. Successful treatment by azacitidine therapy of intestinal Behçet's disease associated with myelodysplastic syndrome. Int J Hematol. 2013;97:520-4.

43. Jung YS, Hong SP, Kim TI, Kim WH, Cheon JH. Long-term clinical outcomes and factors predictive of relapse after 5-aminosalicylate or sulfasalazine therapy in patients with intestinal Behçet disease. J Clin Gastroenterol. 2012;46:e38-45.

44. Sonta T, Araki Y, Koubokawa M, Tamura Y, Ochiai T, Harada $\mathrm{N}$, et al. The beneficial effect of mesalazine on esophageal ulcers in intestinal Behcet's disease. J Clin Gastroenterol. 2000;30:195-9.

45. Nakase H, Okazaki K, Kawanami C, Uchida K, Ohana M, Uose $S$, et al. Therapeutic effects on intestinal Behçet's disease of an intravenous drug delivery system using dexamethasone incorporated in lipid emulsion. J Gastroenterol Hepatol. 2001;16:1306-8. 
46. Toda K, Shiratori Y, Yasuda M, Enya M, Uematsu T, Shimazaki $\mathrm{M}$, et al. Therapeutic effect of intraarterial prednisolone injection in severe intestinal Behçet's disease. J Gastroenterol. 2002;37:844-8.

47. Takada Y, Saigenji K. Is intestinal Behçet's disease in fact an enterocolitis or an ulcer disease, and is steroid treatment useful or harmful? J Gastroenterol. 2003;38:1015-6.

48. Jung YS, Cheon JH, Hong SP, Kim TI, Kim WH. Clinical outcomes and prognostic factors for thiopurine maintenance therapy in patients with intestinal Behcet's disease. Inflamm Bowel Dis. 2012;18:750-7.

49. Iwata S, Saito K, Yamaoka K, Tsujimura S, Nawata M, Hanami $\mathrm{K}$, et al. Efficacy of combination therapy of anti-TNF- $\alpha$ antibody infliximab and methotrexate in refractory entero-Behçet's disease. Mod Rheumatol. 2011;21:184-91.

50. Matsumura K, Nakase H, Chiba T. Efficacy of oral tacrolimus on intestinal Behcet's disease. Inflamm Bowel Dis. 2010;16:188-9.

51. Yasui K, Uchida N, Akazawa Y, Nakamura S, Minami I, Amano $\mathrm{Y}$, et al. Thalidomide for treatment of intestinal involvement of juvenile-onset Behçet disease. Inflamm Bowel Dis. 2008;14: 396-400.

52. Sayarlioglu M, Kotan MC, Topcu N, Bayram I, Arslanturk H, Gul A. Treatment of recurrent perforating intestinal ulcers with thalidomide in Behçet's disease. Ann Pharmacother. 2004;38: 808-11.

53. Travis SP, Czajkowski M, McGovern DP, Watson RG, Bell AL. Treatment of intestinal Behçet's syndrome with chimeric tumour necrosis factor alpha antibody. Gut. 2001;49:725-8.

54. Naganuma $M$, Iwao $Y$, Inoue $N$, Hisamatsu $T$, Imaeda $H$, Ishii $H$, et al. Analysis of clinical course and long-term prognosis of surgical and nonsurgical patients with intestinal Behçet's disease. Am J Gastroenterol. 2000;95:2848-51.

55. Iida M, Kobayashi H, Matsumoto T, Okada M, Fuchigami T, Yao $\mathrm{T}$, et al. Postoperative recurrence in patients with intestinal Behçet's disease. Dis Colon Rectum. 1994;37:16-21.

56. Jung YS, Yoon JY, Lee JH, Jeon SM, Hong SP, Kim TI, et al. Prognostic factors and long-term clinical outcomes for surgical patients with intestinal Behcet's disease. Inflamm Bowel Dis. 2011;17:1594-602.

57. Jung YS, Cheon JH, Park SJ, Hong SP, Kim TI, Kim WH. Clinical course of intestinal Behcet's disease during the first five years. Dig Dis Sci. 2013;58:496-503.

58. Hassard PV, Binder SW, Nelson V, Vasiliauskas EA. Anti-tumor necrosis factor monoclonal antibody therapy for gastrointestinal Behçet's disease: a case report. Gastroenterology. 2001;120: 995-9.

59. Kram MT, May LD, Goodman S, Molinas S. Behçet's ileocolitis: successful treatment with tumor necrosis factor-alpha antibody (infliximab) therapy: report of a case. Dis Colon Rectum. 2003;46:118-21.

60. Lee JH, Kim TN, Choi ST, Jang BI, Shin KC, Lee SB, et al. Remission of intestinal Behçet's disease treated with anti-tumor necrosis factor alpha monoclonal antibody (infliximab). Korean $\mathbf{J}$ Intern Med. 2007;22:24-7.

61. Naganuma M, Sakuraba A, Hisamatsu T, Ochiai H, Hasegawa H, Ogata $\mathrm{H}$, et al. Efficacy of infliximab for induction and maintenance of remission in intestinal Behçet's disease. Inflamm Bowel Dis. 2008;14:1259-64.

62. Lee JH, Cheon JH, Jeon SW, Ye BD, Yang SK, Kim YH, et al. Efficacy of infliximab in intestinal Behçet's disease: a Korean multicenter retrospective study. Inflamm Bowel Dis. 2013;19:1833-8.

63. Byeon JS, Choi EK, Heo NY, Hong SC, Myung SJ, Yang SK, et al. Antitumor necrosis factor-alpha therapy for early postoperative recurrence of gastrointestinal Behçet's disease: report of a case. Dis Colon Rectum. 2007;50:672-6.

64. Saulsbury FT, Mann JA. Treatment with infliximab for a child with Behçet's disease. Arthr Rheum. 2003;49:599-600.

65. Ugras M, Ertem D, Celikel C, Pehlivanoglu E. Infliximab as an alternative treatment for Behçet disease when other therapies fail. J Pediatr Gastroenterol Nutr. 2008;46:212-5.

66. Ariyachaipanich A, Berkelhammer $\mathrm{C}$, Nicola $\mathrm{H}$. Intestinal Behçet's disease: maintenance of remission with adalimumab monotherapy. Inflamm Bowel Dis. 2009;15:1769-71.

67. Chung SH, Park SJ, Hong SP, Cheon JH, Kim TI, Kim WH. Intestinal Behçet's disease appearing during treatment with adalimumab in a patient with ankylosing spondylitis. World J Gastroenterol. 2013;19:5389-92.

68. Hisamatsu T, Ueno F, Matsumoto T, Kobayashi K, Koganei K, Kunisaki R, et al. The 2 nd edition of consensus statements for the diagnosis and management of intestinal Behçet's disease: indication of anti-TNF $\alpha$ monoclonal antibodies. J Gastroenterol. 2014;49:156-62.

69. Pariente B, Cosnes J, Danese S, Sandborn WJ, Lewin M, Fletcher JG, et al. Development of the Crohn's disease digestive damage score, the Lémann score. Inflamm Bowel Dis. 2011;17:1415-22.

70. Kaburaki T, Namba K, Sonoda KH, Kezuka T, Keino H, Fukuhara T, Ocular Behçet Disease Research Group of Japan, et al. Behçet's disease ocular attack score 24: evaluation of ocular disease activity before and after initiation of infliximab. Jpn J Ophthalmol. 2014;58:120-30.

71. Zallot C, Peyrin-Biroulet L. Deep remission in inflammatory bowel disease: looking beyond symptoms. Curr Gastroenterol Rep. 2013;15:315.

72. Maruyama Y, Hisamatsu T, Matsuoka K, Naganuma M, Inoue N, Ogata $\mathrm{H}$, et al. A case of intestinal Behçet's disease treated with infliximab monotherapy who successfully maintained clinical remission and complete mucosal healing for six years. Intern Med. 2012;51:2125-9.

73. Lee HJ, Kim YN, Jang HW, Jeon HH, Jung ES, Park SJ, et al. Correlations between endoscopic and clinical disease activity indices in intestinal Behcet's disease. World J Gastroenterol. 2012;18:5771-8.

74. Schreiber S, Reinisch W, Colombel JF, Sandborn WJ, Hommes DW, Robinson AM, et al. Subgroup analysis of the placebocontrolled CHARM trial: increased remission rates through 3 years for adalimumab-treated patients with early Crohn's disease. J Crohns Colitis. 2013;7:213-21.

75. Van Assche G, Magdelaine-Beuzelin C, D’Haens G, Baert F, Noman M, Vermeire S, et al. Withdrawal of immunosuppression in Crohn's disease treated with scheduled infliximab maintenance: a randomized trial. Gastroenterology. 2008;134:1861-8.

76. Schnitzler F, Fidder H, Ferrante M, Noman M, Arijs I, Van Assche $\mathrm{G}$, et al. Long-term outcome of treatment with infliximab in 614 patients with Crohn's disease: results from a single-centre cohort. Gut. 2009;58:492-500.

77. Colombel JF, Sandborn WJ, Reinisch W, Mantzaris GJ, Kornbluth A, Rachmilewitz D, SONIC Study Group, et al. Infliximab, azathioprine, or combination therapy for Crohn's disease. N Engl J Med. 2010;362:1383-95.

78. Dassopoulos T, Sultan S, Falck-Ytter YT, Inadomi JM, Hanauer SB. American Gastroenterological Association Institute technical review on the use of thiopurines, methotrexate, and anti-TNF- $\alpha$ biologic drugs for the induction and maintenance of remission in inflammatory Crohn's disease. Gastroenterology. 2013;145: 1464-78. 